\title{
Estudo do comportamento físico da substituição parcial de agregado miúdo por resíduo de arenito Botucatu em concreto estrutural
}

\author{
Study of the physical behavior of \\ partial replacement of fine aggregate \\ by Botucatu sandstone residue \\ in structural concrete
}

Sergio Edir Hilario da Silva ${ }^{1}$, Daiana Cristina Metz Arnold ${ }^{1}$ Vinicius de Kaiser Ortolan ${ }^{1}$, José Ernesto de Azevedo Nadalon ${ }^{1}$

\footnotetext{
${ }^{1}$ Universidade Feevale, ERS 239, n. 2755, CEP 93525-075, Novo Hamburgo, RS, Brasil.

e-mail: sergioehs.sh@gmail.com, daim@feevale.br, viniciusortolan@feevale.br, prof_ernesto@ feevale.br
}

\section{RESUMO}

Diversos estudos comprovam a viabilidade da incorporação de resíduos da construção civil no concreto, porém existem lacunas em relação a pesquisas sobre a inserção do resíduo de arenito Botucatu e, nesse sentido, este estudo se propõem a analisar o comportamento físico em concreto estrutural. A construção civil utiliza recursos naturais finitos e a inserção dos rejeitos de Botucatu como substituição do agregado natural pode ser conveniente. Nesta análise, os resíduos de arenito foram caracterizados e selecionados para utilização em dosagens de concreto, com proporções de substituição parcial em 10\%, 20\% e 30\% de agregado miúdo. Foram determinados o desempenho no estado fresco quanto ao abatimento. No estado endurecido, foram determinadas, na idade de 28 dias, absorção de água, massa específica e resistência à compressão. Esta por último apresentou valor potencial, respectivamente, conforme proporção de substituição parcial 32,6; 28,6; 30,8 e 29,6 MPa. Observou, de modo estatístico, que a substituição do agregado miúdo, até o teor de 30\%, se manteve constante no comportamento físico do concreto estrutural.

Palavras-chave: Arenito Botucatu. Agregado Miúdo. Concreto Estrutural. Resistência à Compressão.

\begin{abstract}
Several studies prove the feasibility of incorporating waste from civil construction into the concrete, but there are gaps in relation to research on the insertion of Botucatu sandstone waste and, in this sense, this study aims to analyze the physical behavior in concrete structural. Civil construction uses finite natural resources and the insertion of Botucatu tailings as a replacement for the natural aggregate may be convenient. In this analysis, the sandstone residues were characterized and selected for use in concrete dosages, with proportions of partial substitution in $10 \%, 20 \%$ and $30 \%$ of fine aggregate. Performance in the fresh state for slump was determined. In the hardened state, water absorption, specific mass and resistance to compression were determined at the age of 28 days. This last one presented potential value, respectively, according to the proportion of partial substitution 32,6;28.6; 30.8 and 29.6 MPa. It was observed, in a statistical way, that the replacement of the fine aggregate, up to $30 \%$ content, remained constant in the physical behavior of the structural concrete.
\end{abstract}

Keywords: Botucatu Sandstone. Fine Aggregate. Structural Concrete. Compressive Strength. 


\section{INTRODUÇÃO}

Segundo CARASEK et al. [1], o Brasil consome muitos recursos naturais em obras civis, os quais, conforme RAMOS [2], são objetos de polêmicas que podem suspender a atividade exploratória. Diversos estudos realizados destacam a viabilidade da incorporação de resíduos no concreto, tais como resíduos mistos da construção civil, de concreto ou de mármore e granito [3, 4]. Entretanto, alguns outros necessitam aprofundar estudo, como por exemplo o resíduo de arenito Botucatu, que são necessárias pesquisas para comprovar a viabilidade desta aplicação.

LUZ e ALMEIDA [5] esclarecem que os agregados naturais podem ser substituídos por resíduos para a preparação de concretos. Neste viés, CARASEK et al. [1] complementam que o uso de agregados artificiais vem sendo a solução encontrada pela construção civil para o problema de esgotamento das jazidas naturais.

O conhecimento dos materiais constituintes e uma adequada dosagem do concreto, conforme OLIVEIRA e FENILLI [6] tem importante participação na obtenção de um traço economicamente viável, refletindo em um composto que atende as especificações de resistência e durabilidade exigidas para concreto estrutural. Segundo BORSATTO et al. [7] o arenito da formação Botucatu tem natureza física que favorece a obtenção de agregados miúdos, deixando-o apto geometricamente para ser utilizado em concretos.

A substituição parcial ou total dos agregados naturais por resíduos é uma definição do autor do estudo em prática, pois não há normatização que regule esta técnica, permitindo que variações de dosagens possam ser estabelecidas NEVILLE, A. M [8].

Neste sentido, em relação ao comportamento no estado fresco quanto ao abatimento, PETRY et al. [9] e FIGUEIREDO e VARGAS [4] verificaram que concretos com resíduos de marmoraria e da construção civil e ambos precisaram aumentar a relação a/c na medida que aumentavam o teor de resíduos para se manter inalterado o abatimento. Este método é justificado por SILVA e BELLEI [10] que afirmam ser a diferença no teor de finos dos agregados a razão para aumentar a necessidade de água para um mesmo abatimento, à medida que o percentual de resíduos também aumenta.

Quanto a influência na resistência à compressão, FIGUEIREDO e VARGAS [4] avaliaram concretos com incorporação de resíduos da construção civil nos teores $30 \%, 60 \%$ e $100 \%$, no qual observaram que na idade de28 dias, o traço sem resíduos atingiu a resistência de 33,62 Mpa, enquanto os traços com resíduos, atingiram as respectivas resistências e 31,4 MPa, 34,28 MPa e 16,62 MPa.

Quando a substituição do agregado miúdo se deu por resíduos cerâmicos CORDEIRO [11] encontrou aos 28 dias os seguintes resultados: 24,73 MPa, 20,83 MPa, 19,93 MPa e 21,40 MPa, os quais representam os traços com substituição $0 \%, 10 \%, 20 \%$ e $30 \%$, respectivamente. A a perda de resistência pode ter ocorrido em função da forma angular do agregado reciclado, que interferiu no empacotamento dos grãos.

Ao se analisar um dos parâmetros de durabilidade, a absorção de água também sofre influência quando adicionado resíduos na mistura do concreto ESTOLANO et al. [12] observou em concretos com adição de resíduos de pré-moldados de concreto e constatou que nas misturas com maior percentual de resíduos, em substituição ao agregado miúdo, ocorreu um aumento da absorção de água, fato também evidenciado por ZUCCA et al. [13] e FROTTÉ et al. [14] com resíduos da construção civil.

A massa específica do concreto endurecido e o volume deste, também são influenciados pela alteração dos materiais na produção do concreto, GOMES et al. [17] avaliaram a massa específica de concretos com adição de resíduos da construção civil, encontrando como resultado $1,84 \mathrm{~g} / \mathrm{cm}^{3}$, qualificado como concreto leve. PAZ et al. [18], em concretos com resíduos cerâmicos, encontraram os seguintes resultados, em diferentes percentuais de substituição: $2,31 \mathrm{~g} / \mathrm{cm}^{3}$ ( $0 \%$ de resíduo), $2,28 \mathrm{~g} / \mathrm{cm}^{3}\left(5 \%\right.$ de resíduo), $2,29 \mathrm{~g} / \mathrm{cm}^{3}$ (10\% de resíduo) e $2,27 \mathrm{~g} / \mathrm{cm}^{3}$ (20\% de resíduo), classificados como concreto normal.

A ampla diversidade de resíduos utilizados para produção do concreto apresenta comportamentos físicos distintos, neste sentido, que o resíduo de arenito de Botucatu como agregado no concreto é justificado como inserção nas misturas do concreto, além do mais, é de fácil acesso pois está presente em grande área do território brasileiro, atingindo ainda parte do Paraguai, Uruguai e Argentina. Abrange aproximadamente $1.300 .000 \mathrm{~km}^{2}$, pertencendo à bacia do Paraná e estendendo-se pelo estado do Rio Grande do Sul, passando por Mato Grosso, chegando até Rondônia [7].

No Rio Grande do Sul a formação Botucatu integra o aquífero Guarani e possui formação geológica do tipo arenito, conforme TONDO et al. [19] está presente na bacia hidrográfica do Taquari-Antas, recoberta pelos derrames basálticos da Formação da Serra Geral, com espessura na ordem de 200 metros. Na região do vale do Paranhana o arenito tem espessura que varia de 60 e 200 metros, atingindo extensa área composta por vários municípios, integrando com a Serra Geral até as planícies do Rio dos Sinos [7].

$\mathrm{O}$ arenito Botucatu tem composição granulométrica equivalente a agregado quartzoso, porém com pre- 
sença de finos semelhante a argila [20]. COLARES e ARNS [21] caracterizaram arenito Botucatu, obtendo que mais de $90 \%$ do mineral é passante na peneira $2 \mathrm{~mm}$, ficando retido quase $60 \%$ na peneira $0,074 \mathrm{~mm}$, se assemelhando ao agregado miúdo fino.

GIORDANI [22] descreve a extração de blocos do arenito Botucatu por aberturas de fendas que atingem o plano frágil da rocha por intermédios de ferramentas manuais e pneumáticas, que facilitam a introdução de alavancas e cunhas e desagregam a rocha em grandes placas. Na continuação do processo de extração, estas placas ou blocos são reduzidas para peças menores, que são utilizadas na construção civil em variadas aplicações. A Figura 1 retrata o ambiente da exploração em uma jazida de arenito no vale do Paranhana.

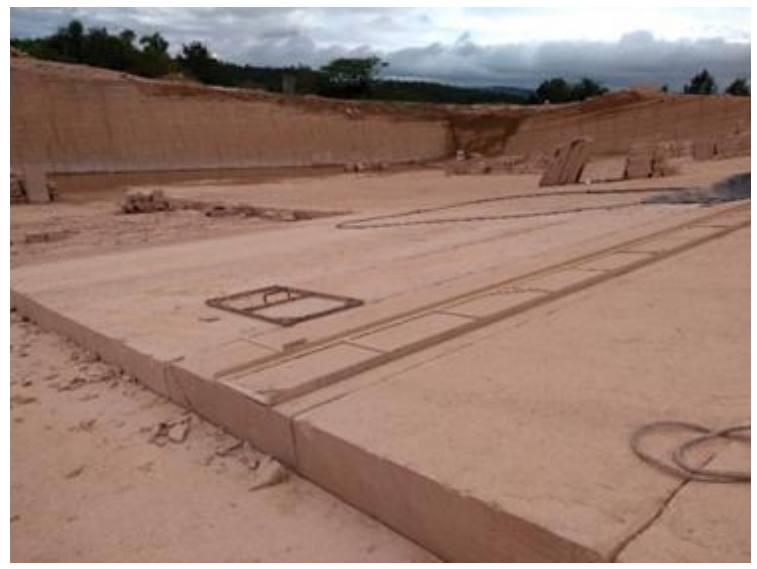

Figura 1: Jazida de arenito Botucatu

O arenito Botucatu é utilizado na construção civil como blocos ou placas de rocha, empregados em revestimentos de pisos, paredes e muros, além de servirem para fins ornamentais e execução de calçadas [21].

Conforme GIORDANI [22] a geração de resíduos nas jazidas de arenito Botucatu é em torno de $30 \%$ da produção de material extraído, uma vez que as sobras ocorrem tanto no momento da extração da rocha, quanto no beneficiamento do produto. No entanto, segundo DOMENICO et al. [23], o aproveitamento de resíduos minerais oriundos de processos da construção civil já é consagrado pela literatura técnica, tornando opção viável para a engenharia, fato comprovado por OLIVEIRA et al. [24], que utilizaram um arenito como agregado miúdo de concreto.

Este trabalho, almeja a verificação do aproveitamento de resíduos de arenito Botucatu, em substituição ao agregado miúdo natural para produção de concreto, a fim de verificar a influência no comportamento físico do concreto no estado fresco e endurecido, além de apurar uma solução ao consumo de recurso natural escasso, conforme alerta de RAMOS [2].

Foram elaborados traços de concreto com substituições de agregado quartzoso por resíduo, de $0 \%$ (referência) $10 \%, 20 \%$ e $30 \%$, sendo posteriormente moldados corpos de prova. No estado fresco foi realizado ensaio de abatimento para analisar o efeito das substituições na trabalhabilidade. Após a desmoldagem, permaneceram em processo de cura por 28 dias para realização dos ensaios de resistência à compressão, absorção de água e massa específica. O traço referência, foi comparado estatisticamente com os demais traços desenvolvidos, validando a incorporação do resíduo.

\section{MATERIAIS E MÉTODOS}

O cimento utilizado foi o CP IV $32 \mathrm{RS}$, que conforme fabricante, possui massa específica de $3,00 \mathrm{~g} / \mathrm{cm}^{3}$.

Para a produção dos concretos, utilizou-se agregados graúdos de origem basáltica e agregados miúdos de origem quartzosa, oriundos do Vale do Sinos e da região da grande Porto Alegre, respectivamente. O agregado graúdo possuí $1369 \mathrm{~kg} / \mathrm{m}^{3}$ e $2,70 \mathrm{~g} / \mathrm{cm}^{3}$ de massa unitária e específica, respectivamente.

Os resíduos de arenito Botucatu foram extraídos em uma jazida no vale do Rio Paranhana, que pelo processo de extração dos produtos são acumulados ao ar livre. Com isso os grãos de fração mais fina são removidos por percolação pluvial e depositados em piscinas artificiais.

Os agregados miúdos foram caracterizados e os resultados são apresentados no item resultados. Para fa- 
cilitar o andamento do presente estudo foram escolhidos resíduos de dimensão semelhante ao agregado miúdo, os quais necessitaram de secagem preliminar, devido ao alto teor de umidade. A Figura 2 demonstra a condição encontrada dos resíduos na jazida (a) e os mesmos após secagem em estufa (b) a $105^{\circ} \mathrm{C}$, por 72 horas.

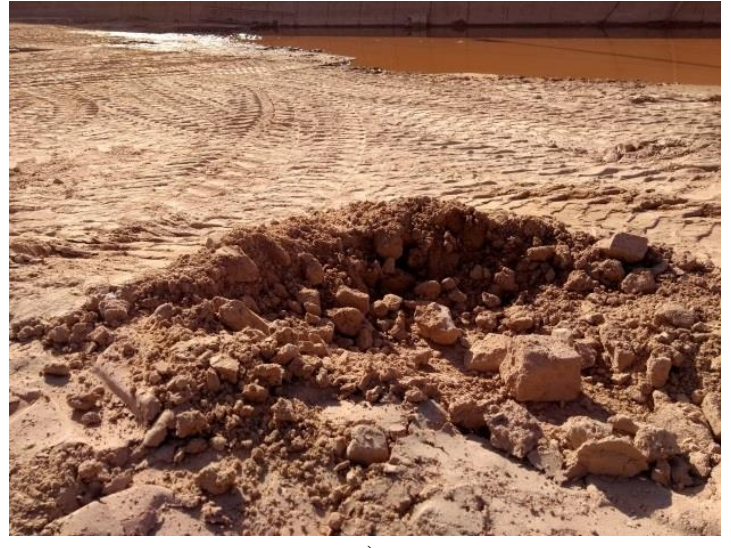

a)

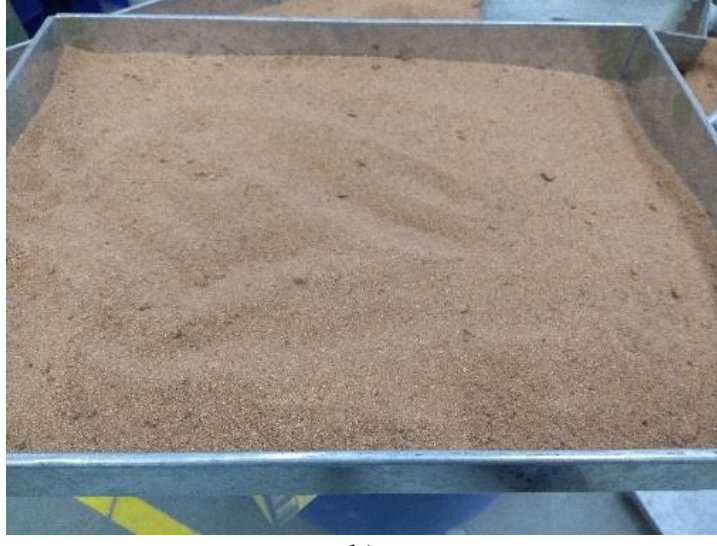

b)

Figura 2: a) Resíduos recolhidos na jazida e b) aspecto após secagem em estufa

Na Figura 2 (b) percebe-se que os resíduos de arenito foram recolhidos em uma condição granulométrica favorável aos ensaios, uma vez que não apresentavam torrões ou sobras de rochas, além de não haver presença de matéria orgânica ou grumos com argila.

O agregado graúdo foi selecionado com auxílio de peneiramento, a fim de garantir somente agregados com diâmetros de $4,75 \mathrm{~mm}$ a $25 \mathrm{~mm}$. Após o agregado passou por processo de lavagem para eliminação das frações menores e de materiais deletérios.

A dosagem do concreto, quanto ao traço e quantidade de materiais, foi determinada a partir do método da ABCP, especificado por CURTI [25]. Portanto, a relação a/c foi definida com a resistência à compressão do concreto requerida aos 28 dias, em $25 \mathrm{MPa}$. Assim, a relação a/c foi fixada em 0,5.

A Tabela 1 descreve o traço referência, assim como de cada mistura, com os volumes dos materiais compensados. Os corpos de prova (CPs) foram denominados como CP0 (referência sem resíduos), CP10 (com $10 \%$ de resíduo), CP20 (com $20 \%$ de resíduo) e CP30 (com $30 \%$ de resíduo).

Tabela 1: Traço unitário do concreto de cada corpo de prova

\begin{tabular}{l|l|l|l|l|l}
\hline CORPO DE PROVA & CIMENTO & $\begin{array}{l}\text { AGREGADO } \\
\text { MIÚDO } \\
\text { QUARTZOSO }\end{array}$ & $\begin{array}{l}\text { RESÍDUO } \\
\text { DE ARENITO } \\
\text { RECICLADO }\end{array}$ & $\begin{array}{l}\text { AGREGADO } \\
\text { GRAÚDO }\end{array}$ & RELAÇÃO A/C \\
\hline CP0 & 1 & 2,04 & 0 & 2,24 & 0,5 \\
\hline CP10 & 1 & 1,838 & 0,202 & 2,24 & 0,5 \\
\hline $\mathrm{CP} 20$ & 1 & 1,636 & 0,404 & 2,24 & 0,5 \\
\hline $\mathrm{CP} 30$ & 1 & 1,434 & 0,606 & 2,24 & 0,5 \\
\hline
\end{tabular}

Previamente, antes da dosagem, os ajustes dos teores de substituição parcial do agregado miúdo foram realizados ainda no estado seco, com a compensação do volume dos agregados reciclados em função do natural, em todas as dimensões dos grãos. As misturas foram efetivadas, conforme cada percentual, ocorrendo a substituição do agregado natural pelo resíduo, mantendo-se a quantidade em massa de agregado fino, na comparação ao traço referência e alterando-se o volume dos agregados em cada traço.

Os concretos foram analisados no estado fresco quanto ao abatimento de tronco de cone, consoante NBR NM 67 [26] e conforme método de dosagem adotado o abatimento foi definido entre 80 e $100 \mathrm{~mm}$. Conforme NBR 5738 [27] foram moldados 6 corpos de prova cilíndricos para cada tipologia de estudo, com dimensões $10 \times 20 \mathrm{~cm}$. Após 24 horas da moldagem os corpos de prova foram desmoldados e alocados em câmara úmida à $23^{\circ} \mathrm{C}$ até 28 dias, idade dos ensaios, quando foram retificadas suas bases. 
Foi determinada a resistência à compressão, conforme método determinado pela norma NBR 5739 [28] em três exemplares, os demais corpos de prova foram ensaiados quanto à absorção de água e determinados o índice de vazios e massa específica.

Para analisar estatisticamente os resultados dos ensaios do concreto endurecido foi adotada a ferramenta Anova, fator único, disponível no Microsoft Excel, a fim de determinar a existência significativa de diferença entre os teores. Para tanto, foi adotado um nível de significância de 5\%, o que define que a confiabilidade da análise é $95 \%$ em relação à existência de hipótese nula. Adicionalmente são feitas avaliações em termos de Coeficiente de Variação (CV), analisando a homogeneidade ou heterogeneidade dos dados.

\section{RESULTADOS E DISCUSSÕES}

Neste capítulo são apresentados e discutidos todos os resultados obtidos nos experimentos, realizados nos concretos moldados, visando permitir que os mesmos possam contribuir para o conhecimento científico.

\subsection{Caracterização Granulométrica do Agregado Miúdo Natural e do Resíduo}

Os agregados miúdos foram caracterizados e obtiveram a distribuição granulométrica do agregado natural, do resíduo e das respectivas misturas, conforme demonstradas nas Figuras 3 e 4.

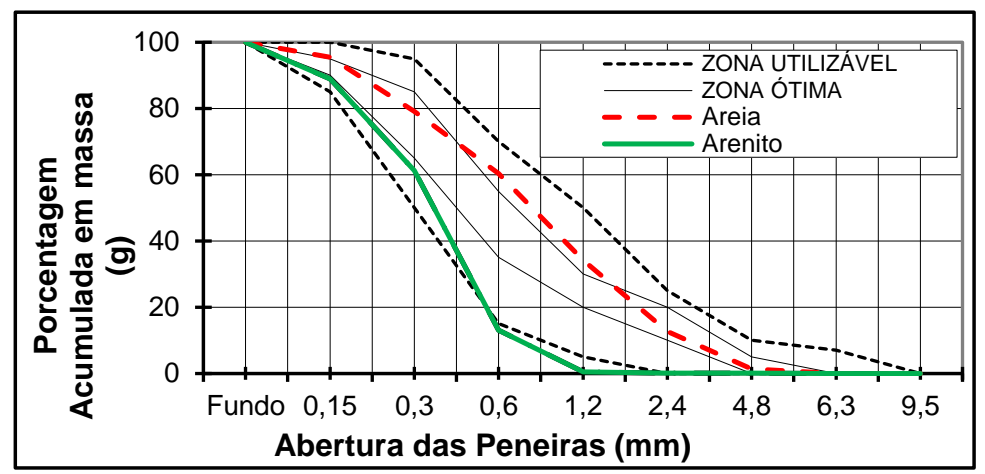

Figura 3: Curva granulométrica do agregado miúdo natural e resíduo de arenito, conforme NBR 7211 [29]

Foi possível observar na Figura 3, que o agregado oriundo de resíduos do arenito Botucatu, nas peneiras com abertura superior a $0,6 \mathrm{~mm}$, encontra-se fora da zona utilizável prevista na NBR 7211 [29], o que demonstrou ser um material mais fino que a areia. De modo geral, o agregado natural e o arenito apresentaram granulometria dentro da zona utilizável.

$\mathrm{Na}$ Figura 4 os resultados das distribuições granulométricas das misturas de agregado quartzoso com $10 \%, 20 \%$ e $30 \%$ de arenito Botucatu são apresentados.

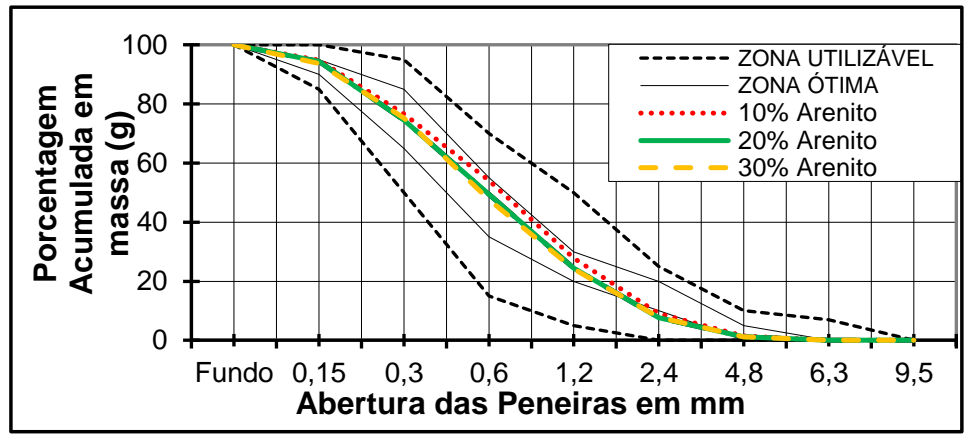

Figura 4: Curva granulométrica dos agregados miúdos nas misturas, conforme NBR 7211 [29]

Na Figura 4 percebeu-se a boa relação dos percentuais estudados com o agregado natural, além do mais, todas as misturas compreenderam a faixa granulométrica ótima da NBR 7211 [29], o que demonstrou que as 
proporções de substituição parcial do agregado natural pelo arenito são viáveis e melhoram a curva granulométrica dos materiais puros.

O comportamento das características granulométricas do arenito Botucatu se deve ao fato de que o mineral tem distribuição mais uniforme, concentrando-se, aproximadamente, $50 \%$ na peneira $0,3 \mathrm{~mm}$. Importante destacar, que as misturas com resíduos tiveram o volume compensado previamente para dosagem do concreto.

Os parâmetros de módulo de finura e diâmetro máximo do agregado natural, do arenito e das misturas são organizados na Tabela 2 .

Tabela 2: Módulo de finura e diâmetro máximo dos agregados miúdos

\begin{tabular}{l|c|c}
\hline AGREGADO & MÓDULO DE FINURA & DIMENSÃO MÁXIMA CARACTERÍSTICA \\
\hline Natural & 2,83 & $4,75 \mathrm{~mm}$ \\
\hline Arenito & 1,64 & $1,18 \mathrm{~mm}$ \\
\hline $90 \%$ natural e 10\% arenito & 2,64 & $4,75 \mathrm{~mm}$ \\
\hline $80 \%$ natural e 20\% arenito & 2,52 & $4,75 \mathrm{~mm}$ \\
\hline $70 \%$ natural e 30\% arenito & 2,50 & $4,75 \mathrm{~mm}$ \\
\hline
\end{tabular}

Os resultados obtidos na Tabela 2 são semelhantes ao encontrado por FIGUEIREDO e VARGAS [4], que caracterizando reciclados de concreto, obtiveram módulo de finura de 2,24 e 2,57 e diâmetro máximo de $4,75 \mathrm{~mm}$.

O módulo de finura dos materiais ensaiados neste estudo se encontrou dentro da zona ótima de 2,20 a 2,90, segundo a NBR 7211 [29]. Com relação ao agregado de arenito Botucatu os parâmetros são menores que o agregado natural e diferem das referências citadas, porém por se tratar de resíduos de origens diversas, a comparação fica prejudicada. Entretanto, segundo a NBR 7211 [29] o módulo de finura do arenito está dentro do limite utilizável inferior, qual é de 1,55 a 2,20, mesmo apresentando resultado maior que a dimensão máxima característica dos grãos.

As massas específicas e unitárias são apresentadas na Tabela 3.

Tabela 3: Massa específica e unitária dos agregados miúdos

\begin{tabular}{l|c|c}
\hline AGREGADO & MASSA ESPECÍFICA & MASSA UNITÁRIA \\
\hline Natural & $2,63 \mathrm{~g} / \mathrm{cm}^{3}$ & $1587 \mathrm{~kg} / \mathrm{m}^{3}$ \\
\hline Arenito & $2,61 \mathrm{~g} / \mathrm{cm}^{3}$ & $1534 \mathrm{~kg} / \mathrm{m}^{3}$ \\
\hline $90 \%$ natural e $10 \%$ arenito & $2,63 \mathrm{~g} / \mathrm{cm}^{3}$ & $1582 \mathrm{~kg} / \mathrm{m}^{3}$ \\
\hline $80 \%$ natural e $20 \%$ arenito & $2,63 \mathrm{~g} / \mathrm{cm}^{3}$ & $1576 \mathrm{~kg} / \mathrm{m}^{3}$ \\
\hline $70 \%$ natural e $30 \%$ arenito & $2,62 \mathrm{~g} / \mathrm{cm}^{3}$ & $1571 \mathrm{~kg} / \mathrm{m}^{3}$ \\
\hline
\end{tabular}

\subsection{Ensaio do Concreto no Estado Fresco}

Os concretos foram ensaiados quanto ao abatimento pelo tronco de cone, visando estabelecer o grau de trabalhabilidade de todos os traços. Os resultados estão expressos na Tabela 4.

Tabela 4: Abatimento pelo ensaio de tronco de cone

\begin{tabular}{c|c}
\hline MISTURA & ABATIMENTO OBTIDO \\
\hline CP0 & $140 \mathrm{~mm}$ \\
\hline CP10 & $180 \mathrm{~mm}$ \\
\hline CP20 & $160 \mathrm{~mm}$ \\
\hline $\mathrm{CP} 30$ & $155 \mathrm{~mm}$ \\
\hline
\end{tabular}

Com resultados apresentados na Tabela 4, foi possível observar que os traços com resíduos atingiram maior abatimento em relação à referência, sem resíduo. A presença de resíduo foi determinante para o aumento do abatimento do concreto, porém a medida que ocorre incremento da quantidade de resíduo o abati- 
mento diminui. Importante destacar que a relação a/c se manteve inalterada, o comportamento do abatimento foi influência apenas pela inserção do resíduo na mistura. Os resultados corroboram com os observados por PETRY et al. [9] e FIGUEIREDO e VARGAS [4], pois há tendência na diminuição da do abatimento na medida que aumenta o teor de substituição por arenito.

Segundo NEVILLE [8], a pasta obtida na hidratação do cimento atua como lubrificante nas partículas do concreto e, neste caso, na incorporação de resíduos, com menor módulo de finura, pode ter aumentado a concentração de finos atuantes. Outro fator que pode ter auxiliado no aumento do abatimento, foi o ajuste na distribuição granulométrica promovida pela substituição parcial do agregado natural por resíduos, o que representou menor índice de vazios e que pode ter atuado na melhora da trabalhabilidade do concreto. NEVILLE e BROOKS [30].

\subsection{Ensaios do Concreto no Estado Endurecido}

Todos os traços de concretos foram ensaiados quanto à absorção de água, índice de vazios, massa específica e resistência à compressão. Em cada tópico foi realizada análise estatística. Os resultados de Absorção de Água e Índice de Vazios são apresentados na Tabela 5.

Tabela 5: Absorção de água e índice de vazios dos concretos

\begin{tabular}{l|c|c}
\hline MISTURA & ABSORÇÃO DE ÁGUA & ÍNDICE DE VAZIOS \\
\hline CP0 & $5,21 \%$ & $11,59 \%$ \\
\hline CP10 & $5,37 \%$ & $11,99 \%$ \\
\hline CP20 & $4,93 \%$ & $10,99 \%$ \\
\hline CP30 & $4,97 \%$ & $11,08 \%$ \\
\hline Coeficiente de Variação & $4,05 \%$ & $4,09 \%$ \\
\hline
\end{tabular}

Com base nos dados da Tabela 5, foi possível observar que os traços com $20 \%$ e $30 \%$ de resíduos, diminuíram os valores da absorção de água e índice de vazios, em relação à referência, porém à medida que foi aumentado o teor de resíduos, há um aumento nos valores da absorção de água e índice de vazios, para as frações analisadas.

A redução encontrada nos traços com 20 e $30 \%$ pode ser explicada pelo melhor empacotamento das partículas, uma vez que o módulo de finura do resíduo de arenito ser menor, o que contribui para o preenchimento dos espaços existentes entre os grãos de maior dimensão, o que corrobora com os resultados encontrados por DOMENICO et al. [23]. Para o traço com 10\%, entende-se que a quantidade foi insuficiente para ocupar os espaços, o resíduo contribuiu para o aumento da absorção de água, já que permanecendo com espaços vazios, aumentou a área superficial, conforme especifica NEVILLE [8].

As determinações das massas específicas dos concretos estudados são apresentados na Tabela 6.

Tabela 6: Massa específica dos concretos $\left(\mathrm{g} / \mathrm{cm}^{3}\right)$

\begin{tabular}{|c|c|c|c|}
\hline MISTURA & $\begin{array}{c}\text { MASSA ESPECÍFICA } \\
\text { SECA }(\rho s)\end{array}$ & $\begin{array}{l}\text { MASSA ESPECÍFICA } \\
\text { SATURADA (psat) }\end{array}$ & $\begin{array}{c}\text { MASSA ESPECÍFICA } \\
\text { REAL ( } \rho r)\end{array}$ \\
\hline $\mathrm{CP0}$ & 2,23 & 2,34 & 2,52 \\
\hline $\mathrm{CP} 10$ & 2,23 & 2,35 & 2,54 \\
\hline CP20 & 2,23 & 2,34 & 2,50 \\
\hline $\mathrm{CP} 30$ & 2,23 & 2,34 & 2,51 \\
\hline Coeficiente de Variação & $0,00 \%$ & $0,21 \%$ & $0,68 \%$ \\
\hline
\end{tabular}

Os resultados demonstraram, de modo geral, que não houve influência dos teores de resíduos na massa específica. A massa específica seca de todos os traços, os qualificam o concreto como normal, de acordo com NBR 8953 [31].

A boa e similar distribuição granulométrica pode explicar a regularidade nos resultados das massas específicas seca e saturada. As pequenas diferenças encontradas na massa específica real têm a mesma justificativa da absorção de água, ou seja, as características granulométricas dos agregados utilizados e as combi- 
nações entre elas.

Analisou-se de forma estatística a influência dos diversos teores de substituição nas características físicas do concreto, para tanto, utilizou-se a ferramenta Anova, considerando o nível de significância de 5\%. Os resultados da análise estatística da massa seca em estufa $\left(\mathrm{m}_{\mathrm{s}}\right)$ são apresentados na Tabela 7.

Tabela 7: Análise dos dados da Anova para $\mathrm{m}_{\mathrm{s}}$

\begin{tabular}{l|l|l|l|l|l|l|l}
\hline FONTE DA VARIAÇÃO & SQ & GL & MQ & F & VALOR-P & F CRÍTICO & SIGNIFICANTE \\
\hline Entre grupos & 1224,22 & 3 & 408,073 & 0,480 & 0,705 & 4,066 & Não \\
\hline Dentro dos grupos & 6797,39 & 8 & 849,673 & & & & \\
\hline Total & 8021,61 & 11 & & & & & \\
\hline
\end{tabular}

Na Tabela 8 é apresentada a análise para os dados obtidos de massa da amostra saturada imersa em água após fervura $\left(\mathrm{m}_{\mathrm{i}}\right)$.

Tabela 8: Análise dos dados da Anova para $\mathrm{m}_{\mathrm{i}}$

\begin{tabular}{l|l|l|l|l|l|l|l}
\hline FONTE DA VARIAÇÃO & SQ & GL & MQ & F & VALOR-P & F CRÍTICO & SIGNIFICANTE \\
\hline Entre grupos & 1321,32 & 3 & 440,439 & 1,058 & 0,419 & 4,066 & Não \\
\hline Dentro dos grupos & 3331,04 & 8 & 416,38 & & & & \\
\hline Total & 4652,36 & 11 & & & & & \\
\hline
\end{tabular}

Os dados encontrados de massa da amostra saturada em água após imersão e fervura $\left(\mathrm{m}_{\mathrm{sat}}\right)$ foram analisados estatisticamente e são demonstrados na Tabela 9.

Tabela 9: Análise dos dados da Anova para $\mathrm{m}_{\mathrm{sat}}$

\begin{tabular}{l|l|l|l|l|l|l|l}
\hline FONTE DA VARIAÇão & SQ & GL & MQ & F & VALOR-P & F CRÍTICO & SIGNIFICANTE \\
\hline Entre grupos & 2283,98 & 3 & 761,325 & 1,014 & 0,436 & 4,066 & Não \\
\hline Dentro dos grupos & 6007,47 & 8 & 750,933 & & & & \\
\hline Total & 8291,44 & 11 & & & & & \\
\hline
\end{tabular}

As análises indicam que os parâmetros avaliados, de todos os concretos, apresentam resultados semelhantes estatisticamente, demonstrando que a substituição do agregado miúdo por resíduos não interferiu nestas características físicas.

Especificamente quanto ao CV o conjunto de dados utilizados nos cálculos das diferentes massas específicas verificadas, assim como na definição da absorção de água, apontam variação de 0,21\% até 4,09\%, o que demonstra pouca dispersão nos resultados, uma vez que valores menores que $15 \%$, podem ser atribuídos a características homogêneas das amostras.

$\mathrm{Na}$ Tabela 10 são apresentados os resultados das resistências à compressão, bem como o desvio padrão e o coeficiente de variação.

Tabela 10: Resistência à compressão dos concretos moldados

\begin{tabular}{l|c|c|c|c}
\hline \multirow{2}{*}{ CORPO DE PROVA } & \multicolumn{4}{|c}{ MISTURA } \\
\cline { 2 - 5 } & CP0 & CP10 & CP20 & CP30 \\
\hline $1(\mathrm{MPa})$ & 30,7 & 25,9 & 30,8 & 27,7 \\
\hline $2(\mathrm{MPa})$ & 26,7 & 27,4 & 29,0 & 29,6 \\
\hline $3(\mathrm{MPa})$ & 32,6 & 28,6 & 30,1 & 27,4 \\
\hline Resistência Potencial (MPa) & 32,6 & 28,6 & 30,8 & 29,6 \\
\hline Desvio Padrão & 3,01 & 1,35 & 0,91 & 1,19 \\
\hline Coeficiente de Variação (\%) & 10,04 & 4,96 & 3,03 & 4,23 \\
\hline
\end{tabular}


Todos os corpos de prova com resíduos apresentam resistência potencial menor em relação ao concreto referência, demonstrando que a substituição do agregado miúdo natural por resíduos influenciou negativamente na resistência à compressão.

Os concretos foram moldados para $25 \mathrm{MPa}$, com margem de segurança de 31,6 $\mathrm{MPa}$, o que de fato ocorreu em todas as amostras moldadas, com exceção apenas do corpo de prova 3 do concreto referência, que atingiu resistência superior ao requerido. Importante referir que todos os CPs atingiram resistência superiores ao valor mínimo estimado. Assim, segundo NBR 8953 [31] todos os concretos são classe C25, podendo ser utilizados para fins estruturais.

A redução da resistência conforme aumento do teor de substituição apresentou comportamento esperado conforme indicado por FIGUEIREDO e VARGAS [4] e CORDEIRO [11].

Quanto ao coeficiente de variação, os dados apontam baixa dispersão nos resultados, demonstrando homogeneidade e validando a utilização da resistência potencial.

A Tabela 11 apresenta os resultados da análise estatística ao ensaio de resistência à compressão.

Tabela 11: Análise dos dados da Anova para resistência à compressão

\begin{tabular}{l|l|l|l|l|l|l|l}
\hline FONTE DA VARIAÇÃO & SQ & GL & MQ & F & VALOR-P & F CRíTICO & SIGNIFICANTE \\
\hline Entre grupos & 16,049 & 3 & 5,350 & 1,628 & 0,258 & 4,066 & Não \\
\hline Dentro dos grupos & 26,293 & 8 & 3,287 & & & & \\
\hline Total & 42,343 & 11 & & & & & \\
\hline
\end{tabular}

Os resultados da análise estatística para as resistências, considerando um nível de significância de 5\% e implicando a um nível de confiança de $95 \%$, constatou-se que os valores de $\mathrm{F}$ são menores em relação ao Fcrítico, o que indica que não há diferença significativa entre a resistência com relação aos teores de substituição parcial do agregado natural por resíduo de arenito Botucatu.

Podendo, então, ser substituído parcialmente o agregado natural, em fração de até $30 \%$, sem prejuízos significativos à resistência à compressão, quando comparado ao concreto sem substituição.

\section{CONCLUSÕES}

Após as análises realizadas pode-se concluir que, dentro das condições de contorno, os resíduos de arenito Botucatu podem substituir de modo parcial até $20 \%$ o agregado miúdo quartzoso no concreto, alcançando o objetivo proposto no presente estudo.

A correção na curva granulométrica do agregado miúdo, ocorrida pela inclusão de percentuais de resíduos de arenito, é ponto de destaque, demonstrando boa interação entre os minerais. Em relação aos resíduos de arenito puro, necessitando de outros estudos investigativos.

O abatimento demonstrou aumento em relação ao traço referência, indicando compatível fluidez nos concretos com resíduos de arenito com o concreto referência, possibilitando margem para reduzir o consumo de água.

Em relação aos resultados da resistência à compressão, em todos os teores de substituição, do agregado miúdo por resíduos de arenito Botucatu, a resistência à compressão se manteve equivalente à obtida no traço referência, comprovando que o comportamento físico dos concretos com os percentuais de resíduos estudado não é alterado. As análises estatísticas realizadas validam a proposta de substituição parcial do agregado miúdo no concreto por resíduos de arenito Botucatu, o que pode se tornar uma opção viável à construção civil.

Investigações por MEV e químicas poderiam contribuir nos esclarecimentos dos comportamentos físicos e químicos das misturas, que resultaram nos resultados físicos no estado endurecido e fresco dos concretos estudados. 


\section{BIBLIOGRAFIA}

[1] CARASEK, H., ARAUJO, R.C., CASCUDO, O., et al., "Parâmetros da areia que influenciam a consistência e a densidade de massa das argamassas de revestimento", Revista Matéria, v. 21, n. 3, pp. 714-732, jul./set. 2016.

[2] RAMOS, G.G.C., Proposta de cenários para a atividade de mineração de areia no Guaíba (RS), Dissertação de M.Sc., Universidade Federal do Rio Grande do Sul, Porto Alegre, RS, Brasil, 2019.

[3] GOMES, P.C.C., PEREIRA, F.A., UCHÔA, S.B.B., et al., "Obtenção de blocos de concreto com utilização de resíduos reciclados da própria fabricação dos blocos”, Ambiente Construído, v. 17, n. 3, pp. 267-280, jul./set. 2017.

[4] FIGUEIREDO, N., VARGAS, A., Análise da influência do uso de agregados reciclados da região de Criciúma/SC nas propriedades mecânicas de concretos estruturais, Trabalho de Conclusão de Curso (Artigo) - Curso de Engenharia Civil, Universidade do Extremo Sul Catarinense, Criciúma, SC, Brasil, 2016.

[5] LUZ, A.B., ALMEIDA, S.L.M., Materiais substitutivos (alternativos) - Manual de Agregados para a Construção Civil, 2. ed., Rio de Janeiro, CETEM - Centro de Tecnologia Mineral, 2012.

[6] OLIVEIRA, É.A., FENILLI, F.G., Estudo de dosagem para determinação de traço de concreto, Trabalho de Conclusão de Curso (Monografia) - Curso de Engenharia Civil, Universidade do Sul de Santa Catarina, Palhoça, SC, Brasil, 2019.

[7] BORSATTO, S., DANI, N., RIBEIRO, R., et al., "Mapeamento geológico do município de Igrejinha para uso geotécnico", In: $15^{\circ}$ Congresso Brasileiro de Geologia de Engenharia e Ambiental, 392, Bento Gonçalves, RS, Brasil, out. 2015.

[8] NEVILLE, A.M., Propriedades do concreto, 5a. ed., Porto Alegre, RS, Bookman, 2016.

[9] PETRY, N.S., DELONGUI, L., MULLER, Á.L., et al., “Avaliação do uso de resíduos de marmoraria na produção de concretos", Revista de Arquitetura IMED, v. 6, n. 2, pp. 71-92, jul./dez. 2017.

[10] SILVA, B.M., BELLEI, P., "Substituição parcial e total do agregado miúdo utilizando resíduo de revestimento cerâmico na argamassa de revestimento", ANAIS - Engenharia Civil, v. 1, n. 1, pp. 24-42, jul. 2018.

[11] CORDEIRO, A.S.S., "Análise de resistência mecânica de concreto com agregado de origem cerâmica”, Revista Técnico-Científica do CREA-PR, ed. 18, pp. 1-19, abr. 2019.

[12] ESTOLANO, V., FUCALE, S., FILHO, J.O.V., et al., “Avaliação dos módulos de elasticidade estático e dinâmico de concretos produzidos com agregados reciclados oriundos de resíduos de pré-fabricados de concreto", Revista Matéria, v. 23, n. 1, pp.1-13, 2018.

[13] ZUCCA, R., NETO, J.G.V., SANTOS, R.C., et al., "Uso de resíduos de construção como agregado graúdo destinado à confecção de blocos para alvenaria de vedação", Enciclopédia Biosfera, v. 15, n. 27, pp. 1381-1392, jun. 2018.

[14] FROTTÉ, C., NUBILA, C.S.A., NAGALLI, A., et al., "Estudo das propriedades físicas e mecânicas de concreto com substituição parcial de agregado natural por agregado reciclado proveniente de RCD", Revista Matéria, v. 22, n. 2, pp. 1-17, jun. 2017.

[15] ASSOCIAÇÃO BRASILEIRA DE NORMAS TÉCNICAS (ABNT), NBR 9778: argamassa e concreto endurecidos - determinação da absorção de água, índice de vazios e massa específica, Rio de Janeiro, 2009.

[16] ASSOCIAÇÃO BRASILEIRA DE NORMAS TÉCNICAS (ABNT), NBR 12655: concreto de cimento Portland - preparo, controle, recebimento e aceitação - procedimento, Rio de Janeiro, 2015.

[17] GOMES, P.C.C., ALENCAR, T.F.F., SILVA, N.V., et al., "Obtenção de concreto leve utilizando agregados reciclados”, Ambiente Construído, v. 15, n. 3, pp. 31-46, jul./set. 2015.

[18] PAZ, M.K.A., FREITAS, J.L.M., ALMEIDA, E.; et al., “Avaliação da substituição parcial da areia de rio por resíduos de blocos cerâmicos estruturais em concreto convencional”, Journal of Engineering and Technology for Industrial Applications, v. 5, ed. 18, pp. 132-137, jun. 2019.

[19] TONDO, R., DEBONI, H.L., GEDOZ, S.C., “Água mineral termal em poço tubular profundo na bacia do Paraná, Pinto Bandeira- RS”, In: XIX Congresso Brasileiro de Águas Subterrâneas, Campinas, SP, Brasil, set. 2016.

[20] FLORIANO, C.F., CONTE, M.A.G., BRESSANI, L.A., “Avaliação microscópica do contato aderente entre nata de cimento e arenito Botucatu”, In: IX Seminário de Engenharia Geotécnica do Rio Grande do Sul - GEORS, Caxias do Sul, RS, Brasil, abr. 2017. 
[21] COLARES, F.S., ARNS, P., Reaproveitamento de resíduos de arenito da formação Botucatu em infraestrutura rodoviária, Trabalho de Conclusão de Curso (Artigo) - Curso de Engenharia Civil, Universidade do Extremo Sul Catarinense, Criciúma, SC, Brasil, 2015.

[22] GIORDANI, C., Viabilidade técnica do uso de resíduo do beneficiamento de arenito como substituição do agregado miúdo em argamassas, Trabalho de Conclusão de Curso (Monografia) - Curso de Engenharia Civil, Universidade Federal do Rio Grande do Sul, Porto Alegre, RS, Brasil, 2014.

[23] DOMENICO, P., LIMA, T.T., CASTRO, R.M., et al., "Influência do agregado miúdo reciclado na resistência à compressão e porosidade do concreto", Revista Internacional de Ciências, v. 8, n. 3, pp. 129-147, jan./jun. 2018.

[24] OLIVEIRA, E., ANDRADE, F.C., MINICUCCI, L.A., et al., "A utilização de rocha sedimentar como agregado de concreto: a experiência da UHE Colíder”, In: XXX Seminário Nacional de Grandes Barragens, Foz do Iguaçu, PR, Brasil, mai. 2015.

[25] CURTI, R., "Dosagem de concreto: importância, parâmetros e ajustes laboratoriais (Método ABCP)", In: Concrespaço: Rodado do conheCimento, São Paulo, SP, Brasil, ago. 2015.

[26] ASSOCIAÇÃO BRASILEIRA DE NORMAS TÉCNICAS (ABNT), NBR NM 67: determinação da consistência pelo abatimento do tronco de cone, Rio de Janeiro, 1998.

[27] ASSOCIAÇÃO BRASILEIRA DE NORMAS TÉCNICAS (ABNT), NBR 5738: concreto - procedimento para moldagem e cura de corpos de prova, Rio de Janeiro, 2016.

[28] ASSOCIAÇÃO BRASILEIRA DE NORMAS TÉCNICAS (ABNT), NBR 5739: concreto - ensaio de compressão de corpos de prova cilíndricos, Rio de Janeiro, 2018.

[29] ASSOCIAÇÃO BRASILEIRA DE NORMAS TÉCNICAS (ABNT), NBR 7211: agregados para concreto - especificação. Rio de Janeiro, 2019.

[30] NEVILLE, A.M., BROOKS, J.J., Tecnologia do concreto, 2a . ed., Porto Alegre, RS, Bookman, 2013. [31] ASSOCIAÇÃO BRASILEIRA DE NORMAS TÉCNICAS (ABNT), NBR 8953: concretos para fins estruturais - classificação pela massa específica, por grupo de resistências e consistência, Rio de Janeiro, 2015.

\section{ORCID}

Sergio Edir Hilario da Silva

Vinicius de Kayser Ortolan

Daiana Cristina Metz Arnold

José Ernesto de Azevedo Nadalon https//orcid.org/0000-0003-0811-3205

http://orcid.org/0000-0002-6952-3147

https://orcid.org/0000-0002-0048-3028

https://orcid.org/0000-0003-3466-3921 